\title{
Climate Change Challenges to Accounting
}

\author{
Constancio Zamora Ramírez, José María González González
}

Department of Accounting and Finance, University of Seville, Seville, Spain.

Email: constancio@us.es

Received December $2^{\text {nd }}, 2012$; revised January $10^{\text {th }}$, 2013; accepted February $5^{\text {th }}$, 2013

\begin{abstract}
Low carbon economy is causing the implementation and development of carbon markets that affect an increasing organizations number. These markets entail new challenges to accounting practitioners. The aim of this paper is, on the one hand, to know how the financial statements are being affected by the obligations of companies to control and compensate their carbon emissions, by analyzing the different positions adopted by both regulatory organizations and companies in the practice; and, on the other hand, to analyze the content and specific problematic of accounting statements that report on emissions in physical terms. This paper considers the accounting treatment of new carbon assets and liabilities which external information is not sufficiently regulated. Also, the paper analyzes the new contractual relationships that are being developed such as complex derivative structures, purchasing carbon units through ERPAs (Emissions Reduction Purchase Agreements), carbon monetization, carbon collateralization and carbon funds. Finally, new report requirements to companies that are arising, like Carbon Accounting or risks and strategies regard to climate change (Carbon Reporting), are also analyzed.
\end{abstract}

Keywords: Climate Change; Carbon Assets; Carbon Markets; Carbon Finance; Weather Derivatives; Catastrophe Bonds; Carbon Accounting; Carbon Reporting

\section{Introduction}

In the past years we have been able to appreciate a continuous increase in the organizations' overall interest to measure their Greenhouse Gasses emissions (hereinafter, GHG), with the goal of reducing or compensating them. The for-profit companies that are also interested in measuring their GHG emissions are not limited solely to those that have a productive model that is highly linked to the consumption of fossil fuels, since they include services companies and even financial institutions. In this sense, we can say that the control and reduction of emissions of the organizations fighting against climate change are raising important challenges to Accounting [1-4].

The organizations are getting involved in the emissions control and reduction processes, either because they are submitted to a regulatory framework or because they decided to do so willingly. Organizations can also decide to submit voluntarily to the obligation of controlling and reducing their emissions and reporting them, for different reasons which may include: their own corporate responsibility policy, a better assessment of the company, their products or services by their clients; better access to financial resources or the search of influence on the regulations that could be implemented in the future [5]. In these cases, carbon assets can fulfill different functions, including the compensation of emissions of all or part of the activities of the company or offering the market $\mathrm{CO}_{2}$ neutral products, in which case, clients might be willing to pay an additional charge for this "added value".

Similarly, the carbon units can be used in a great range of operations between companies [6]. On the one hand, these operations can rise from the company's management of the different risks that are related to these assets, normally related to the evolution of different market components, among others: their prices, energy prices and the relation between the main fuels, as well as the relationship between volumes and prices of the different types of carbon emission assets. On the other hand, the carbon units can be a source of resources that the companies can access in different ways.

Carbon units fundamentally form the mechanisms for mitigation in the fight against climate change. However, with this same goal, we will find specific financial instruments through which companies can manage the risks deriving from climate and natural disasters, which result in the rise of the so called adaptation mechanisms.

We can suppose that the economic effects of the emissions, as well as the different assets and operations developed for their management, may affect the accounting balances in many different ways. There are instruments and operations that are perfectly framed within the International Accounting Reporting Standards (IFRSs), and the International Accounting Standards (IASs), both is- 
sued by the International Accounting Standard Board (IASB). However, the lack of agreement on the true nature of carbon assets has hindered the necessary consensus so that the practice accepts IASB's efforts to regulate the accounting of emission rights.

On the other hand, the supply of information regarding emissions no longer constitutes one sole problem which may have a greater or smaller impact on traditional financial statements. The social and political awareness of the environmental impact of the entrepreneurial activity has resulted in the inclusion of sustainability reports in their financial information. In these reports we can find real financial statements of emissions, in which the economical fluxes of monetary units have been replaced by flows of tones of $\mathrm{CO}_{2}$ emissions, including notes in which, instead of commenting on the accounting principles and policies used for the preparation of this information, we find the specifications of the measurement standards of these emissions.

Consequently, the carbon economy implies a large range of legal, economical, and financial problems, as well as in terms of the information provided by the company which we will analyze in this paper from the point of view of their impact on the information revealed by organizations. Likewise, we will consider if these new problems can be solved or not by the current accounting regulations, thus contributing to identify those specific aspects in which Accounting research can offer answers and, in general, all the aspects related to the revelation of information by the companies in regards to a low-carbon economy.

To comply with this goal, in the following sections of this paper, we have considered the accounting treatment of the new carbon assets and the economical obligations linked to the low-carbon economy, whose reporting in the financial statements still have not been regulated definitively. Furthermore, we will analyze the accounting implications of these new contractual relationships that have been developed on carbon units, under derivative structures, as forms of future acquisitions of these assets by means of Emissions Reduction Purchase Agreements (ERPAs), carbon monetization, carbon collateralization and carbon funds. Moreover, we will show the accounting implications of the operations in the adaptation markets. Lastly, we will analyze the information standards that are arising for organizations, both to elaborate and report on carbon inventories (Carbon Accounting) as well as showing the references to risks and strategies related to climate change (Carbon Reporting).

\section{Reference Regulations and Practices for the Financial Accounting of Carbon Assets}

Although the European market has been working for over half a decade, the debate on the nature of the assets de- riving from them still hasn't been closed, which not only affects their accounting treatment, but also their tax considerations and other legal issues. The difficulty to adapt their nature to the legal effects is determined by the variety of their origin, function and implications for the company:

- The diversity of carbon units that arise from these markets.

- The different purposes for which they can be used in an institution and their different sources: for the compliance with the legal obligations for the emissions of their facilities, for the compliance of voluntarily acquired commitments and even, with mere speculative purposes regarding their prices.

- The acquisition of carbon units that, for example, can take place through the reception of derivative rights in an assignment plan, direct purchases from third parties or through a platform the compliance of forward or option contracts or the participation in a carbon fund.

- Participation in these markets implies for the company the recognition of liabilities in their balance sheets of the obligations resulting from issuing the emissions subject to this regime.

As the first international reference regulation we can mention the Uniform System of Accounts de la Federal Energy Regulatory Commission (FERC) of 1993 in the United States of America, for energy companies and utilities. Emission rights, in this case, were for the emissions of sulphur dioxide-acid rain-established in the amendments of the 1990 Clean Air Act. Despite the time elapsed since this act and its diversion from the rest of the regulations, as we will see below, there are practices in many companies that comply with the same.

Both the Financial Accounting Standard Board (FASB) as the IASB have had failed experiences in terms of the issuance of statements in this regard. FASB eliminated from their agenda the EITF 03-14 Participants' Accounting for Emissions Allowances under a "Cap-and-trade" Program, based on a regulation issued by FERC. The reasons to eliminate this EITF is mainly based on the dimension of the problematic that this document should address (beyond a cap-and-trade program), as well as the inconsistencies of the document (based on FERC regulation) with the rest of the FASB standards [7].

IASB wanted to prepare a statement of the International Financial Reporting Interpretations Committee (IFRIC) before the implementation of the emissions rights European market. Thus, in December 2004 they issued the IFRIC Interpretation 3, Emissions Rights, with the purpose of seeking a greater consistency with the regulatory corpus of this body. However, it didn't have the support of the European Financial Reporting Advisory 
Group (EFRAG), which resulted in its elimination by IASB. Currently, this project has been stopped. The main characteristics of this regulation were:

- A consideration of the European emission rights as intangible assets subject to the International Accounting Standard (IAS) 38.

- The valuation of these assets in their recognition would be at their fair value, therefore the listing as assets acquired from the government at a price that is null or lower than market value should appear on the balance sheet as a government grant (subject to IAS 20), which would imply the recognition of deferred revenue. This revenue would appear as a liability on the balance sheet, outside equity, and would be allocated to the result of the year on the basis of a systematic base during the compliance period, regardless of if these assets (carbon units) were maintained or transferred.

- Once these assets had been recognized, they would maintain their initial value, except for corrections due to deterioration. However, the re-evaluation model foreseen for intangible elements in IAS 38 could be applicable.

- The emissions developed would give way to the recognition of a liability subject to IAS 37 (Provisions, Contingent Liabilities and Contingent Assets). Therefore, the debt should be recognized for the amount necessary to compensate these emissions in the present, in other words, at the fair value of the amount equivalent to those emission rights.

Although the carbon markets and the climate change economy are in constant expansion, the accounting standards still do not have a necessary consensus. This has resulted in a remarkable divergence in the development of practices by corporations in relation to the reflection of all the equity effects that could derive from the implication in low-carbon markets and projects. Therefore, when studying how these aspects affect the financial statements, we should also consider how these practices are being developed. The entrepreneurial practices have developed actions that are not fully consistent with the IFRSs. In 2007, PricewaterhouseCoopers (PwC) conducted a study [8] regarding these practices, not only focusing on the accounting of EUAs and the emissions obligations of the companies, but also on CERs.

We must bear in mind that the aforementioned documents refer to very specific assets, more specifically European emission rights, but the problem is extensive to other carbon assets, as well as the obligations and operations resulting from the company's participation in other carbon markets, within the Kyoto Protocol or not. However, the joint project with FASB, Emissions Trading Schemes, has suggested a more extensive scope for capand-trade regimes of mandatory compliance, so that it may include any regulation for voluntary regimes ${ }^{1}$.

The analysis below regarding the accounting implications of the participation in a carbon market will be done by using as a reference all the documents mentioned in this section.

\section{Balance Elements Generated by the Carbon Markets: Presentation and Valuation}

\subsection{Balance Sheet Presentation}

Basically, we can identify three elements that could appear in a balance when a company takes part in a carbon market: assets for carbon units, liabilities for the obligations resulting from the correct regime that the company is ascribed to, deferred income (or equity, in its case) for the emission rights received for free or for a price below their fair value. The operations on these assets as those developed in the adaptation markets will be addressed in Sections 4 and 5.

For the carbon assets, with their maximum exponent in the EUA, in general, the conceptual Accounting framework can point us towards an independent presentation in the balance. In fact, the control that the company exercises on these assets is independent of its obligations; the organization can transfer them once these rights have been assigned, having the obligation of rendering an amount of rights equaling the tonnes of $\mathrm{CO}_{2}$ emitted in the past.

The register of the accounting implications of an emissions regime can be done showing a net amount in the balance [9] between the allowances maintained by the institution and their amount which should be provided for the actual emissions (including an amount for the same, lessening the asset). If there were not enough permits, this net amount would imply including a liability in the balance. Thus, the described register was included by FERC in their regulation Uniform System of Accounts, in which the emissions permits were considered as stock inventories, to be valued at a historical cost by using the weighted average cost, so that those delivered by the government freely would have an accounting value equal to zero. The value of this asset would be reduced, collecting the corresponding cost as the emissions of sulphur dioxide would take place.

The accounting nature of the batch for carbon assets, in addition to being considered in certain environments as an inventory, has been proposed as a financial instrument and an intangible asset, the latter is what seems to obtain a larger consensus among regulators for their pre-

\footnotetext{
${ }^{1}$ We will later refer to this project in different sections of this paper. It can be read in the following links: http://www.ifrs.org/Current+Project s/IASB+Projects/Emission+Trading+Schemes/Emissions+Trading+Sc hemes.htm and http://www.iasplus.com/agenda/emissiontrading.htm
} 
sentation in the balance.

The carbon assets could hardly be treated as financial instruments, given that, although they could be considered as a means of payment to cancel the liabilities assumed by the company's emissions, they lack a contractual nature, or the bilaterality of the definition of a financial instrument, since it gives way to "a financial asset of one entity and a financial liability or equity instrument of another entity" (IAS 32, Section 11). In itself, it does not comply with the financial asset definition, since they are not cash, net instruments, cash receivables financial assets, or contracts to exchange financial instruments. The PwC (2007) survey does not include a practice that treats these assets as financial instruments.

As regards to the treatment of these assets as stocks, on the one hand, they are considered in the Uniform System of Accounts, which affects all of the power utilities of that country. On the other hand, the PwC study (2007) showed that $15 \%$ of the surveyed companies, when dealing with EUAs, and $38 \%$ of the surveyed companies, when related to CERs, treated these carbon assets as inventories. Inventories are those assets (IAS 2, Para. 6): 1) held for sale in the ordinary course of business; 2) assets in the production process for sale in the ordinary course of business; or 3) materials and supplies that are consumed in production, or the rendering of services. Section 1) is fulfilled if part of the activity were to purchase or sale these rights in the ordinary course of business. Section 2) is not fulfilled, since they are not undergoing a production process. As regards to Section 3), these assets could not be easily framed. Although they could be considered as another supply, necessary for the production process, of with the special connotations that constitute a right to develop an action (emissions of gasses), which do not imply the reception of a material or a service. We must bear in mind that the amounts of the assets required by an entity would depend more or less directly on the production that is developed in this period.

However, it seems that the consensus ended up considering them as intangible assets, given the greater accommodation of these emissions rights and credits following the definition of IAS 38, Para. 8: an identifiable non-monetary asset without physical substance. The aforementioned survey reported it in the following way: of the surveyed companies, $65 \%$, in the case of EUAs and 38\%, in the case of CERs, considered them as intangible assets. Although the last joint meetings between IASB and FASB reaffirm the nature of the assets of these rights and the independent record of the obligations that they imply, their nature still has not been treated.

Another matter that has been discussed in the IASBFASB joint project is the possibility of recognizing as assets all the carbon units that the company will receive during the years that form a compliance period during which the company has decided to be a part of the voluntary market, regardless of if these have not been delivered.

\subsection{Assets Recognition per Carbon Units}

\subsubsection{Initial Recognition and Value}

If the assets have been acquired in the market at a price equivalent to their fair value, this price will be their initial value. However, the main problem lies in how to value the assets received for free or for a price lower than their fair value. This happens to many companies when they receive emissions rights through a national designation plan, normally at zero cost. In some cases, they could have supported a certain cost, but different from their fair value, because they have been acquired through an auction system or because the company is developing a project with which it would obtain CERs, for instance.

In regards to the freely received assets, in general, the statements or regulatory projects opt for the recognition of these assets at market value, as recommended in the revoked IFRIC 3 and IAS 38. However, there are other positions in favour of the initial null valuation which would imply a distancing from the conceptual framework, as we can find in some statements, as the one included in the US FERC, and the practices of certain companies (76\% of the companies surveyed by PwC, 2007). This initial null valuation or at cost (if it exists) is backed up by the practice precisely because it eliminates volatility problems in the results that other more conceptually consistent alternatives would entail.

The case that the carbon assets are generated by the company itself in the development of some project for the reduction of emissions have not been contemplated in any project of the regulation. Given that the generated carbon units (CERs, although others could also be used, as ERUs or VERs) are obtained in compliance with the main production of the project, it is probable that the calculation of the production costs would be less reliable than recording these assets in the balance at their fair value, recognizing the corresponding exploitation income. The fair value will be the most consistent alternative if these assets are considered as intangible assets, which is the treatment given by $13 \%$ of the companies surveyed by PwC. $29 \%$ of them recognizes their production costs as inventories; while $29 \%$ does not recognize it until they are sold or compensated.

In the IASB-FASB joint project, they also reinforced the position of the initial valuation at fair value, given that it provides more transparent and relevant information for decision making.

\subsubsection{Measurement after Recognition}

Regarding the subsequent valuation, the possibilities offered by the statements are also very different. The FERC 
regulation proposes a valuation at a cost that, in case of being units received for free, would continue at zero cost.

Under IAS 38, we could adapt the revaluation model. This model consists of valuing at fair value after the recognizing the carbon assets. In this case, the increases should be included in the net assets like "other comprehensive income”, directly allocating the lessening of value to losses and earnings. However, the increases recognized in the equity will become part of the distributable funds when these assets are eliminated, and what the case would be if these were used to compensate emissions. This model could not be applied under PGC, since it does not consider the treatment of immobilized assets.

In the aforementioned IASB-FASB joint project, further valuation to fair value is supported by most of the members of the committee (meeting of September 2010 and subsequent meetings), both for those allocated for free as those acquired from third parties. Its impact in the results would be compensated by the liabilities assumed by the commitments of emissions deriving from the market regime under which the company is ascribed. However, the recognition of an income could be derived if it is expected that part of the carbon units received exceed the foreseen emissions, although this matter is in an initial development phase.

In regards to the impairment, not only would it be done under the cost model, as well as under the revaluation model, since the IAS 38, the lessening of values, once the former increases in the net assets can be recognized, it would imply the recognition of the development against equity (for the loss of revaluations that have already been registered in the equity) or to the result, if the recoverable amounts were below the cost.

\subsubsection{Reception of Free Assets or for Amounts below Their Fair Value}

According to the aforementioned PwC survey, the free reception of rights is recognized at a null value by most companies. However, when these carbon units are acquired for free, they receive an initial valuation, normally obeying their fair value and it should correspond to a counterpart that would be recognized as a subsidy or donation. In IASB, the free reception of carbon units as deferred income (IAS 20), is shown as the liabilities of the balance. In some accounting systems, like the Spanish one, subsidies and donations are included as an amount in other comprehensive income.

The imputation of this subsidy to the result of the year will be done systematically, as shown in paragraph 12 (IAS 20), which will obey the emissions of gases that will be compensated with the received units. In the survey developed by $\mathrm{PwC}_{\mathrm{w}}$, this was also the second criteria followed by most of the surveyed companies (50\%). A similar treatment is applied when the assets are not received for free, but for an amount lower than fair value.
Another possibility, further from the conceptual framework, but put into practice according to the aforementioned survey (although in a lower percentage), is the recognition as income directly in the result of the year for the carbon assets received freely (total or partially).

\subsection{Liabilities That Arise from the Carbon Markets}

The emissions of a company subject to a market, imply the recognition of a liability at the year end, by means of the recognition of a provision, for the compensation obligations through the delivery of the carbon-units equivalents, normally EUAs or CERs.

Under a cost model, the provision would be registered against profit and losses, for those emissions developed during the period, in an amount equivalent to the accounting value of the carbon assets which should be delivered for their compensation. In the event that there were not enough units, the assets that should have been acquired to annul such emissions would be increased by the market value at the year end. In the FERC regulations we should consider the units acquired by means of allocation plans, they will not have an assigned value, which would reduce the amount of the provision, since it would be calculated by an average weighted price of the carbon units in the portfolio. This model, in which the liabilities assumed by the subsidies are valued in terms of the allocated value to the rights previously received, were also followed by most of the surveyed companies (47\%) in the PwC survey. It is interesting to observe that this same item in the survey also considered the prices hired under forward purchase options subscribed by the company (26\%).

Under the international regulations, these liabilities should be initially valued at the market value of the carbon units required to cancel the obligations of the emissions during that period. This is due to the fact that the amount of a provision should be the higher estimate, at the date of the balance, and the necessary payment for the cancellation of the present obligation (IAS 37, Para. 2).

The broader focus adopted by the IASB-FASB project, covering other markets such as the voluntary markets, has been to consider if the reception of carbon units could imply the immediate appearance of an obligation, since the company has assumed a certain level of efficiency in their emissions under the regime, and therefore would result in a liability. If these units were received for free from a state, under the IASB regulations, this liability appears due to its free reception ${ }^{2}$. In a meeting held in October 2012, most of the members of the committee chose an initial and subsequent valuation of these liabilities at

${ }^{2}$ In IAS 20, the subsidies can be considered as deferred income (liabilities), and not income directly attributable to the net equity contemplated in the PGC. 
their fair value. However, they considered the alternative of the valuation being subject to a "business model" such as the one used for financial instruments. In October and November 2010, they debated if an excess of emissions foreseen regarding the allotted carbon units, should give way to a liability prior to the development of the efficient excess of emissions, which were still without solving the form of recognition and valuation of this liability.

In this last meeting, the presentation of the carbon assets and the liabilities for emissions have also been considered, it is currently under debate if the assets and liabilities should be presented independently or in a net form, under a "linked-presentation", as long as the company has the intention of compensation.

\section{Accounting of Operations with Carbon Assets}

Most of the operations that use carbon units as the underlying adopt the structure of financial derivatives (futures, options, etc.) and, accordingly, are within the scope of IAS $39^{3}$.

Although the underlying does not create a financial instrument, its changes of value determine the change in the value of the contract to acquire or sell carbon assets. This treatment implies that the changes of value of these contracts (or clauses) within the scope of IAS 39 should be attributed to the losses and earnings of the period.

In addition to the negotiation of these contracts in platforms, the companies can enter into agreements that have the same structure or that have clauses that adopt the form of a derivative agreement and, therefore, are also within the scope of IAS 39. A special reference should be made of ERPAs, private contracts through which investors and promoters negotiate the transmission of credits that a project will generate in the future. When these close or condition the price at which these credits will be transmitted, the agreement adopts the structure of a forward or an option.

However, the treatment as a derivative of these contracts in the financial statements of a company can be considered as outside the scope of the regulation, thanks to the exclusion established in paragraph 5 , which prescribed that IAS 39 shall be applied to those contracts to buy or sell a non-financial item that can be settled net in

\footnotetext{
${ }^{3}$ As we can observe in paragraph 9: "A derivative is a financial instrument or other contract within the scope of this Standard with all three of the following characteristics 1 ) its value changes in response to the change in a specified interest rate, financial instrument price, commodity price, foreign exchange rate, index of prices or rates, credit rating or credit index, or other variable, provided in the case of a non-financial variable that the variable is not specific to a party to the contract (sometimes called the 'underlying'); 2) it requires no initial net investment or an initial net investment that is smaller than would be required for other types of contracts that would be expected to have a similar response to changes in market factors; and 3) it is settled at a future date.”
}

cash or another financial instrument, or by exchanging financial instruments, as if the contracts were financial instruments, with the exception of contracts that were entered into and continue to be held for the purpose of the receipt or delivery of a non-financial item in accordance with the entity's expected purchase, sale or usage requirements.

Therefore, a body that negotiates with these carbon assets to purchase or sell them through these contracts, because it is part of its activity, is not required to treat these transactions as financial derivatives from an accounting point of view. This can be the case of a company that owns facilities affected by EU ETS or the promoter of a project that generates credits for the reduction of emissions. It is important to highlight that to claim this exclusion, the volume of the contract should be done in relation to the body's expected purchases, sales or needs. The entrepreneurial practice in fact uses this possibility, given that the PwC survey [8] states that $46 \%$ and $31 \%$ of surveyed companies claim this exception for contracts on EUAs and CERs, respectively.

We should also highlight that if these contracts are net settled, it would not be possible to claim this exception, as previously stated in Para. 5 and specified in Para. $6^{4}$. This way, for example, if the company adopts the practice of acquiring EUAs through a forward and sells them immediately, it cannot leave similar forwards outside of the balance. It could happen that the contracts include purchase-sale clauses of carbon units. Depending on how these are articulated, they could proceed to the separation of the implicit derivative, or not. Normally, the main element of analysis for a separate presentation of the derivative is if it shares the nature and risk of the main contract. This is precisely the condition established by IAS 39 (Para. 11):

- In the case of cap and floor options on a variable established price (cap, floors, collars), these should be outside of the money and not levered at the beginning

\footnotetext{
${ }^{4}$ Paragraph 6 of IAS 39 establishes different ways by which a contract for the purchase or sale of non-financial items can be liquidated at their net amount, in cash or by means of another financial instrument, or through the exchange of financial instruments. These include:

- when the terms of the contract permit either party to settle it net in cash or another financial instrument or by exchanging financial instruments;

- when the ability to settle net in cash or another financial instrument, or by exchanging financial instruments, is not explicit in the terms of the contract, but the entity has a practice of settling similar contracts net in cash or another financial instrument or by exchanging financial instruments (whether with the counterpart, by entering into offsetting contracts or by selling the contract before its exercise or lapse);

- when, for similar contracts, the entity has a practice of taking delivery of the underlying and selling it within a short period after delivery for the purpose of generating a profit from short-term fluctuations in price or dealer's margin; and

- when the non-financial item that is the subject of the contract is
} readily convertible to cash. 
of the contract, as specified in the Application Guide of IAS 39 (Para. AG 33b), since otherwise, the clause would imply the separate recognition of an implicit derivative.

- The price of the contract can be indexed with different references. Obviously, if it refers to an index or a listed price of carbon assets, it would share the risks and the nature of the main contract and their separation would be unnecessary. But there is no longer a specific guide for those cases in which it is not a price of the same asset. We understand that if this asset is very similar to the one negotiated in the contract, it would be unnecessary to separate it; for example, CERs or VERs are purchased and their price is referred to a EUA listing. Another very common case is to list the contract at the price of a commodity, which normally maintains a close relation with the value of carbon units. In this case they would require a more detailed analysis, but it is true that the prices of raw materials or supplies such as carbon, oil, electricity, etc., are closely related with the quoting of EUAs and CERs, which could lead to the conclusion that this separation is not necessary ${ }^{5}$.

Another alternative accounting treatment for these contracts on carbon assets is the application of hedge accounting, normally by means of cash flow hedge accounting, since these are usually used to hedge the transactions foreseen in these activities. This would imply that their changes in value are included, completely or partially, as income and expenses in other comprehensive income. However, the practice included in the aforementioned survey is not to use this accounting mechanism, since barely $7 \%$ of the surveyed companies use it in the case of EUAs. For the specific case that the hedged item is an operation foreseen as highly probable ${ }^{6}$, the accounting hedging that would correspond would be cash flow, imputing the changes of value of the derivative to the net equity in the part that has not been determined as an effective hedging.

On the other hand, in operations such as monetization and collateralization, their accounting treatment is equal to a loan, in which the funds that will be received from an ERPA will be destined fully or partially to the payment of the same. Therefore, they should be registered as such loans. However, in the case of a monetization it could

\footnotetext{
${ }^{5}$ Paragraph $33 \mathrm{f}$ of the AG of IAS 39 contemplates the indexing of a lease of an inflation index of the economical environment of the entity as a derivative that shares the nature and the risks inherent to the host project, as long as at the time of the agreement they are outside of the money and are not leveraged. Therefore, we consider that we could believe that the indexation of the contracts on carbon assets are commodities with a close relationship between their price which will not result in the separation of the same as an implicit derivative, with the exception that the conditions of non-leverage and contracting "outside of money" are respected.

${ }^{6}$ We consider that this could be the most frequent situation.
}

be an anticipated purchase-sale of carbon assets, but for this it would be necessary that the seller of the carbon assets does not have to complete future deliveries of CERs with additional provisions in the case that the value of these assets did not achieve the amount of the received funds.

Another interesting matter is the treatment that should be given to the participation in carbon funds. We must consider that these funds are not constituted under the regulation of a normal investment fund, but they are legally considered as joint property ${ }^{7}$. On the other hand, the performance obtained by the investors does not correspond with the delivery of financial instruments, but with carbon assets (EUAs or CERs, normally). This results in the fact that the accounting treatment of these participations does not coincide with those of a normal investment fund, in which performance is obtained normally in cash and, therefore, is outside of the regulations regarding financial instruments. In our opinion, these participations should be treated in a similar way as to how the company treats credits for directly managed projects, in other words, as intangible assets or inventories, considering the regulations relating to a joint account.

\section{Accounting of Operations in Adaptation Markets: Weather Derivatives $Y$ Catastrophe Bonds}

Climate change has meant that many companies develop new financial instruments in order to "accommodate" their income statements to the effects of climate change. Along this line, climate derivatives and disaster bonds have risen as adaptation financial mechanisms.

In regards to climate derivatives, their treatment will be similar to those of any other derivative when these are negotiated in an organized market ${ }^{8}$. The accounting treatment of these instruments was the purpose of the debate, given the function of the same as insurances. In fact, the original wording of IAS 39, revised in 2003, excluded these contracts from their focus (Para. 2h). However, in a subsequent revision of this regulation in 2004, NIIF 4 eliminated this exception and only considered the exclusion of those contracts that really acted as insurance, that is, within the scope of NIIF 4 (IAS 39, GA 1).

For a contract to have the condition of an insurance in the accounts under NIIF 4, the insurer accepts a significant insurance risk from the other party (the holder of the insurance policy), agreeing to compensate the holder if a future uncertain event (the insured event), adversely affects the holder of the insurance. Under this premise, most of the climate derivatives will not comply with the conditions of the insurance, since the covered underlying

\footnotetext{
${ }^{7}$ It can be read in the FC2e Website (http://www.fc2e.com), which recommends this treatment to their participants.

${ }^{8}$ The largest negotiation platform is CME.
} 
condition cannot affect the hiring party adversely, in other words, it simply speculates on the evolution of the variable. On the other hand, it does not establish mechanisms that evaluate this party in this case. Simply, in the event of an evolution of a given climatic, geological or any other physical variable, one of the parties of the derivative contract must pay the other party, depending on the notional and calculation formulas specified in the contract. In conclusion, climatic derivatives should be accounted for as derivatives, in other words, recording the assets and liabilities that correspond to the assumed rights and obligations, and valuing them at their fair value in profit or loss. To allow for them to be registered as insurance, these contracts should only produce settlements if the holder suffered losses as a result of the covered event.

As for catastrophe bonds, they are a hybrid instrument case, which is subject to the scope of IAS 39. The host contract would be a debt instrument and the embedded derivative a climate derivative, in the form of a swap, in which the issuer would pay a premium to the investor (excess interest rate paid on the returns that correspond to a normal bond with the same risk and maturity); while the issuer, in the case that the covered event occurred, would receive a compensation equal to the nominal value or interests that they would not have to pay.

- In order to propose the accounting treatment that the issuer and bondholder should apply, we must remember the conditions relating to the accounting obligations of separating embedded derivatives (IAS 39, Para. 11).

- The economic characteristics and risks of the embedded derivative are not closely related to the economic characteristics and risks of the host contract; in this case, a bond, its risks are linked to the issuer's ability to pay and the interest rates, which are not shared with the risks inherent to weather derivatives, whose underlying variables would be measures of rain, wind, earthquakes... Thus, both the issuer and the holder must recognize and value both components separately.

- A separate instrument with the same terms as the embedded derivative would meet the definition of a derivative; obviously it has a variable that is not related to one side (climatic-physical phenomenon), leveraged (the interest paid on these instruments is well below the amount that would cease to be paid in case of occurrence of the event-nominal or bond interest), and have a maturity date (that of the bond).

- The hybrid (combined) instrument is not measured at fair value with changes in fair value recognized in profit or loss, this is, a derivative that is embedded in a financial asset or liability measured at its fair value with changes in the profit or loss for the period would not be separated.

From the point of view of the issuer, unless the liabil- ity was measured at fair value, the bond would be valued at amortized cost. Its initial value would result from the difference between the initial fair value of the entire instrument and the value related to the embedded derivative. The effective rate to be applied to calculate the amortized cost should equal the initial value thus calculating the flows that correspond to a bond, considering for the compensation an interest rate equivalent to a debt emission during the same period and by an issuer of a similar risk.

The investor in these products may encounter more diverse problems. If they were valued in their entirety at fair value through profit or loss, it would not be required to separate the incorporated climatic derivative. If this were not the case, separation would be required, so that the initial value of the bond (the host contract) is calculated by the difference between the initial fair value of the entire instrument and the corresponding embedded derivative. The main contract, as of this moment, would be valued depending on the category of financial assets in which they have been included. In any case, it will be necessary to calculate their amortized cost, in a similar way as we have specified in the preceding paragraph. Lastly, if the investor applies IFRS 9, this type of financial assets would be valued at fair value through profit or loss, since they are hybrids; their main contracts are treated at the same time as the financial instruments.

\section{Carbon Accounting}

For the development of a low-carbon economy it is necessary to have procedures for calculating the amount of $\mathrm{CO}_{2} \mathrm{e}$ emitted by different sources, or stored, in the case of a sump. These procedures are known as Emissions Accounting, Carbon Capture and Storage (Carbon Accounting).

Carbon Accounting requires a protocol or approach for the development of inventories and carbon footprints, built under a series of principles that provide these measures with sufficient reliability. To do this, it is necessary to follow a set of principles, similar to those under which financial information is drafted: relevance, integrity, consistency, transparency and accuracy $[10]^{9}$. Any standard for carbon accounting should be consistent with the principles of the Intergovernmental Panel on Climate Change (IPCC), since otherwise, the generation of carbon credits would not be possible, even if the development of the standards considered the requirements of the regulations of all the carbon markets [9].

The most extended protocol today is the GHG Protocol [10], which was promoted by the World Resources

\footnotetext{
${ }^{9}$ The Greenhouse Gas Protocol Initiative was created in the United States, since this country has not ratified the Kyoto Protocol, although it has had a broad dissemination even among several signatory companies.
} 
Institute and the World Business Council for Sustainable Development [11]. This protocol is applied to over 63\% of the companies included in US Fortune 500. Another regulation pursuing this same purpose is standard ISO 14064-I.

Emission inventories not only have the purpose of estimating the emissions of a body, but they should serve as a tool for the development of emissions reduction strategies, the establishment of goals and the support to make investment decisions.

The inventory should be defined in terms of two variables:

- Area of Responsibility: is the definition of the limit to which a body will assume the posting of the emissions of their subsidiaries. There are two mechanisms: the first, under which they would assume emissions in the proportion of their share; and the second, which would assume the integrity of the emissions of all the participated companies with a domain of 51\%. However, although both are simple and objective criteria, it is clear that situations requiring a greater complexity of these methods can be easily found.

- Scope Level: Refers to those sources or origins of emissions that will be controlled in the inventory. Normally, a higher scope level involves higher complexity in the calculations, as well as the assumption of a hypothesis. The GHG Protocol establishes three scope levels, the first two are of required control under this standard: Scope 1) based on those sources that are owned or directly controlled by the entity, such as combustion boilers for the production of electricity or heat. This is the case also for the company's own vehicles. Scope 2) emissions related to the electricity that is acquired from third parties, therefore it would be important that the utility company would provide as accurate a measure as possible of the emissions of the electricity consumed by its clients. Scope 3) under which the rest of the company's indirect emissions are incorporated, such as those generated by the movement of employees in public transportation, the freight developed by third parties, those generated for the development of consumption required for production, etc. This is the most complex level measured precisely due to the lack of information and the complexity of the required methodology. Therefore, its application is often not absolute, but many companies specify this level with a limited scope.

In some cases, under a level of Scope 1) they control a very high percentage of the volume of emissions (e.g. a carrier), while in others, most of the emissions are concentrated in the indirect character developed by third parties to supply goods and services to companies (e.g. consultants).

In capital markets there is a process to audit the information that entities provide to investors. Similarly, it is necessary in the field of carbon markets for two reasons. On the one hand, to verify that inventories provided its investors has been developed according to a certain standard. And on the other hand, carbon assets should generate enough confidence in their potential investors, for which is necessary that such units are generated according to the requirements of the regulatory regime under which they are traded. This is especially important for CER credits or other units generated under the umbrella of the voluntary markets, such as the Gold Standard or the Voluntary Carbon Standard.

As a proof of the importance that the information audit related to the carbon inventories is reaching, the International Auditing and Assurance Standard Board (IAASB), dependent organism of the International Federation of Accountants (IFAC), has approved a final draft of the ISAE 3410 (2011) regulation, Assurance Engagements on Greenhouse Gas Statements, which is consistent with ISAE 3000, Assurance Engagements Other than Audits or Reviews of Historical Financial Information.

ISAE 3410 recognize that, in many cases, the audit of emissions would require a report with a limited scope. In any case, the standard does not prescribe specific procedures, as in the case of financial reporting, but the particularity of the object of the analysis implies that the auditor should select the most appropriate ones for the circumstances of the regime under which these emissions are measured, based on the valuation of errors risks in these emissions reports. In the report, both the limited scope and a reasonable insurance should include a summary of the procedures.

\section{Carbon Reporting}

The investors' demands for information on sustainability are growing. Within these demands, the one related to the emissions of bodies is becoming stronger, having several reasons for this interest, including:

- Institutional investors, such as investment funds, that are demanding this information to develop investment strategies between companies with a certain sustainability profile.

- Certain international indexes such as the Dow Jones Sustainability Indexes, Global 100, Best in Class, among others, that specifically require such information.

- Some governments that require certain bodies to publish their emissions reports, as in the case of the state of California, New South Wales or the UK [9].

Information on emissions can be issued in several ways, among which we must highlight three. First, the standards of the Global Reporting Initiative (GRI), under which most sustainability reports are drafted. Under the GRI, companies must report their emissions, although they do not require a very thorough detail (GRI, 2006). 
A second mechanism in which major global corporations collaborate is the Carbon Disclosure Project (CDP), promoted in the year 2000 by 35 institutional investors that were aware of the risks that were not covered by investments in sectors of higher environmental impact, as well as the impact of new regulations, which could affect profitability adversely. The number of members has continued to increase, reaching - in the last survey in 2012534 investors, with a total volume of assets of 64 trillion dollars.

The CDP questionnaire is completed by over 3000 companies worldwide. This questionnaire comprises 5 areas: risks and opportunities of climate change, accounting of GHG emissions, additional issues on GHG accounting, performance and corporate governance. Based on these responses, the CDP has created the Carbon Disclosure Leadership Index (CDLI).

There is now a third effort to improve and expand information on climate change provided by the companies conducted by the Climate Disclosure Standards Board (CDSB) [12], whose promoters include the CDP. Its aim is to standardize information on climate change in company reports. Specifically, the proposal is to include this information in the management report, based on the principles issued by the accounting regulators (IASB) or related to sustainability (World Resources Institute, WRI, World Business Council for Sustainable Development, WBCSB, and International Organization for Standardization, ISO). Their proposal of a conceptual framework is still in a draft phase, but in its contents we can differentiate:

1) Management commentary, including: a) strategies developed by the company to reduce the impact of climate change on the company itself; b) main risks and opportunities for the business related to climate change; c) corporate governance, understanding the decision-making level within the organization and controlling the actions related to climate change; d) yield: presentation of charts and graphs of all relevant indicators to judge the impact on costs and benefits for the company of the set of actions and their effects on climate change; e) regulatory regimes affecting the company.

2) Statement of Greenhouse Gas Emissions, which collect emissions for different scope levels. For comparative purposes, not only should it include the statement for the year, but it should also the figures of the previous year and the baseline data. To complement this, carbon intensity indicators should be included (e.g. tone/€ of revenue), for the year, the year prior and the baseline. These inventories could be supplemented with sector averages.

3) The Notes to the Greenhouse Gas Emissions Statement would provide an explanation to properly interpret the inventory: a) information policy related to the inventtory: GHGs included, businesses/activities/geographical area of the group, or those that are being measured or excluded, levels of scope and/or their limits, their conversion factors and sources or standards, explanation of the baseline, verification of the compensation and their sources; b) emission Inventory according to different sources for each of the levels of the scope.

4) Independent Assurance Report: which expresses its scope, that is, what inventory information has been verified, the purpose for which the audit report was prepared, the standards that have been followed for the measurement of the inventory, the audit process, limitations, and, lastly, the auditor's opinion on whether the inventory information fairly reflects the reality of the company's emissions. To do this, the standards that IAASB will issue in the future should be considered.

\section{Conclusions}

Throughout this paper we have shown how the climate change economy affects the external information provided by the company. For operations with carbon units and the adaptation market, international law provides a clear framework for accounting purposes, as we have discussed above. However, the most important matter of a low-carbon economy remains pending, that is, the nature and the accounting reflection of the carbon assets from mitigation markets.

The IASB and the FASB should complete the project related to the emissions markets. This regulation should cover not only the classic carbon assets (EUAs and CERs), but it should have a certain degree of abstraction that is sufficient to consider the derived assets from any market, both of a regulated and voluntary character. In any case, the accounting treatment of emissions rights should be based on the entity's business model and intended use of the rights.

The academic world has an important role, supporting the development of these standardization processes. Given the variety of existing practices, it would be useful to shed light, through research projects, on the most convenient practices for the decision-making processes of the users. However, research in this area should not only cover the standardization of financial information. As we have seen above, the information on carbon inventories, as well as the information regarding the risks and strategies related to climate change, will be incorporated to the information supplied by the bodies. Accounting professsionals should also be partly responsible for what characteristics this information should have, as well as to where and how it is provided.

\section{REFERENCES}

[1] J. Bebbington and C. Larrinaga, "Carbon Trading: Accounting and Reporting Issues,” European Accounting 
Review, Vol. 17, No. 4, 2008, pp. 697-717. doi:10.1080/09638180802489162

[2] P. Mete, C. Dick and L. Moerman, “Creating Institutional Meaning: Accounting and Taxation Law Perspectives of Carbon Permits," Critical Perspectives on Accounting, Vol. 21, No. 7, 2010, pp. 619-630. doi:10.1016/j.cpa.2010.03.006

[3] J. Andrew and C. Cortese, "Accounting for Climate Change and the Self-Regulation of Carbon Disclosures," Accounting Forum, Vol. 35, No. 3, 2011, pp. 130-138. doi:10.1016/j.accfor.2011.06.006

[4] M. J. Milne and S. Grubnic, "Climate Change Accounting Research: Keeping It Interesting and Different,” Accounting, Auditing \& Accountability Journal, Vol. 24, No. 8, 2011, pp. 948-977. doi:10.1108/09513571111184715

[5] K. Tang, "A Guide to Carbon Finance: Carbonomics for a Credit Constrained World,” Risk Books, London, 2009.

[6] C. Zamora Ramírez and J. M. González González, "Contribution of Finance to the Low Carbon Economy," Low Carbon Economy, Vol. 2, No. 2, 2011, pp. 62-70.

[7] J. Fornaro, K. Winkelman and D. Glodstein, “Accounting for Emissions,” Journal of Accountancy, Vol. 208, No. 1,
2009, p. 40.

[8] Price Waterhouse Coopers, “Trouble-Entry Accounting. Uncertainty in accounting for the EU Emissions Trading Scheme and Certified Emission Reductions,” 2007. http://www.ieta.org/assets/Reports/trouble_entry_account ing.pdf

[9] J. Ratnatunga, “An Inconvenient Truth about Accounting," Journal of Applied Management Accounting Research, Vol. 5, No. 1, 2007, pp. 1-20.

[10] The Greenhouse Protocol, “A Corporate Accounting and Reporting Standard—Revised Edition,” 2010. http://www.ghgprotocol.org/files/ghgp/public/ghgprotocol-revised.pdf

[11] M. A. Hashmi, “A Complete Guide to the Global Carbon Market: Profiting in a Low-Carbon World,” Max Energy, Mankato Estados Unidos, 2008

[12] Climate Disclosure Standards Board (CDSB), "The Climate Disclosure Standards Board Reporting Framework. Exposure Draft,” 2009.

http://www.cdsb-global.org/index.php?page=draft-reporti ng-framework 